\title{
DOSSIÊ
}

Sociologias, Porto Alegre, ano 4, № 7, jan/jun 2002, p. 122-135

\section{Regulação em saúde: análise de conceitos fundamentais}

JAUICE DORHEIIES DE CASTIO

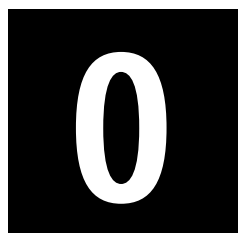

propósito deste artigo é discutir se as leis da oferta e demanda se aplicam ao "mercado da saúde", estudar as inúmeras falhas de mercado que ocorrem e que, conseqüentemente, indicam que grau de intervenção deve o Estado ter no setor.

Segundo a teoria de oferta e demanda, é através da livre competição que se define a quantidade ótima a ser produzida em uma dada sociedade. 0 preço é determinado quando se alcança o perfeito equilíbrio entre a oferta e a demanda (Mansfield, 1978; Calmbach, 1969; Simonsen, 1969).

No entanto, para que as forças de mercado - "a mão invisível" - atuem, é necessário que existam as condições de perfeita competição. Q uando uma das condições de perfeita competição não ocorre, defrontamonos com o que é chamado de uma falha de mercado. A existência de falhas de mercado justifica a intervenção do Estado na economia. A intensidade da intervenção dependerá diretamente da intensidade dessas faIhas (D onaldson \& Gerard, 1993; McGuire, Henderson, M oney, 1992).

A seguir, pretendemos discutir as falhas de mercado que ocorrem no setor saúde e justificam a intervenção do Estado para alcançar a otimização na alocação e na distribuição dos recursos. Iniciaremos por introduzir os principais conceitos da teoria, pois, conforme a teoria da oferta e demanda é no mercado, por meio do mecanismo dos preços, que se obtém a maior racionalidade na produção, na alocação e na distribuição dos bens e serviços.

* Dra. em Saúde Coletiva pela Unicamp e professora da Universidade Estadual do Rio Grande do Sul e do Centro de Ciências Econômicas da Unisinos. 
Há três conceitos fundamentais para a compreensão desta teoria: oferta, demanda e mercado. A oferta é quanto de uma mercadoria será produzida por um determinado preço, ou seja, focaliza o lado dos produtores. A demanda é o desejo por um bem ou serviço, combinado com a capacidade e a habilidade de fazer este desejo conhecido e realizado, isto é, analisa 0 lado dos consumidores. E o mercado é um mecanismo de ajuste entre a oferta e a demanda que permite a troca de bens e serviços entre produtores e consumidores, sem a necessidade da intervenção do Estado, pois utiliza como indicadores os preços. Então, dado o preço de mercado de determinado bem ou serviço, os produtores vão ofertar suas mercadorias e os consumidores vão consumi-las de acordo com suas rendas, seus desejos e necessidades, além da estrutura organizacional e institucional da sociedade.

Em condições de perfeita competição, o equilíbrio de mercado corresponde à situação em que os produtores maximizam seu lucro, e os consumidores maximizam a sua utilidade. Sendo assim, segundo esta teoria, o mercado alcança o máximo de utilidade possível, dados os recursos disponíveis na sociedade.

A partir da redefinição e da adaptação dos conceitos mais gerais, Donaldson e Gerard (1993) consideram como condições de perfeita competição para o setor, as seguintes:

\section{Racionalidade}

0 pressuposto da racionalidade é de que o consumidor sabe com clareza o que quer consumir, quando e onde conseguir, portanto, o consumo pode ser planejado.

\section{Inexistência de externalidades}

São os efeitos colaterais produzidos pelo consumo ou pela produção de um bem por outras pessoas, que afetam o indivíduo de forma positiva ou negativa. No caso, ele não tem controle sobre esses efeitos colaterais e, 
tampouco, sobre os custos ou benefícios que auferirá. Podemos considerar uma externalidade positiva a vacinação e, negativa a poluição. 0 mercado, na presença de externalidades, não tem como considerar a totalidade dos custos e benefícios gerados pelo consumo ou produção do bem, mas apenas do produtor e do consumidor diretos.

\section{Perfeito conhecimento do mercado por parte do consumidor}

O consumidor sabe o que quer consumir, conhece todas as opções disponíveis e consegue julgar as diferenças de qualidades entre elas, portanto, optará pelo consumo do bem ou serviço que maximizar a sua utilidade. 0 acúmulo de conhecimento é também determinado pela regularidade com que $o$ indivíduo usa o mercado e, desta forma, aprende com os erros.

\section{Consumidores agindo livremente em seu benefício}

Podem decidir livremente, em seu próprio interesse, sobre o que consumir ou não.

\section{Numerosos e pequenos produtores sem poder de mercado}

Num mercado de concorrência perfeita, presume-se a existência de inúmeros pequenos produtores sem o poder de influenciar o mercado; a competição entre eles se dará na base dos preços.

Estes são os pressupostos para que o mercado realize, eficientemente, a sua função na produção, distribuição e alocação de bens e serviços em condições ideais. No entanto, essas condições idealizadas não se encontram tão facilmente na realidade: observam-se imperfeições de grau variado em cada mercado como, por exemplo, as falhas de mercado, que são imperfeições que ocorrem quando uma ou mais das condições de perfeita competição não estão presentes. Segundo esta teoria, a intensidade dessas falhas vai 
definir uma maior ou uma menor necessidade de intervenção do Estado na economia com o objetivo de maximizar o bem-estar na sociedade. Normalmente o governo atua, no lado da demanda, subsidiando renda para determinados grupos (aposentados, deficientes, desempregados), e, no lado da oferta, através de subsídios para produtores.

O caso da saúde parece ser especial já que, segundo Donaldson e Gerard (1993), nenhuma das condições de perfeita competição está presente, e, neste caso, justifica-se uma ação mais intensa do Estado.

A seguir, analisaremos as características consideradas como as principais falhas de mercado que ocorrem no setor da saúde, as suas inter-relações e as conseqüências. As principais falhas de mercado são as seguintes: (a) ocorrência de riscos e incerteza; (b) "risco moral" 1; (c) externalidades;

(d) distribuição desigual da informação; (e) existência de barreiras .

\section{a) $O$ corrência de riscos e incerteza}

A ocorrência da doença é imprevisível. Por conseguinte, não é possível planejar individualmente o consumo futuro de cuidados de saúde.

A resposta de um mercado não regulado pelo Estado, nestas circunstâncias, é o desenvolvimento de mecanismos de seguros privados de saúde que garantiriam o ressarcimento das despesas com cuidados de saúde.

Entretanto, os seguros privados de saúde apresentam alguns problemas. As companhias de seguro privado, além doscustosadministrativose marketing, também auferem lucros. Por isso, o custo do prêmio do seguro tem que ser maior que o custo efetivo com possíveis cuidados de saúde que o segurado venha a necessitar. O u seja, os segurados estão pagando por outras despesas além daquelas relacionadas com cuidados de saúde. Mas, porque os indivíduos são avessos ao risco, eles se dispõem a pagar e, assim, garantirem-se contra a possibilidade de incorrer em grandes perdas financeiras em caso de doença.

1 Este termo deriva do inglês "M oral Hazard" e não tem tradução adequada para o português, seria melhor descrito como o risco de não adotar a atitude mais racional do ponto de vista do consumidor pelo fato de ter todos os cuidados de saúde cobertos pelo seguro. 
Aparentemente esta é uma solução para responder ao problema da incerteza quanto ao futuro; no entanto, no mercado de seguro privado de saúde ocorrem também falhas, que são as deseconomias de escala, a seleção adversa e o risco moral.

A economia de escala ocorre quando as grandes companhias distribuem seu custo fixo entre todos os seus produtos e, assim, conseguem uma diminuição no custo por unidade de produto. A desvantagem da existência de economia de escala é a tendência à formação de monopólios que passam a determinar sozinhos o preço do mercado, já que não têm concorrentes, e o consumidor não tem escolha.

A deseconomia de escala ocorre no mercado de seguro-saúde quando são muitas pequenas companhias competindo entre si, cada qual com custos diferentes. Isso significa um custo final, por unidade de produto, maior. O u seja, o custo final de seguro será maior para o consumidor.

A seleção adversa, outra falha de mercado que ocorre no seguros privados de saúde, é a exclusão de alguns grupos do acesso ao segurosaúde. Num mercado competitivo, as companhias de seguro, por não terem um pleno conhecimento do mercado, não sabem os riscos a que cada indivíduo está submetido; sendo assim, calculam o valor do prêmio com base num risco médio.

Contudo o consumidor sabe mais sobre as suas condições de saúde e, quando percebe que seu risco é menor do que a média, opta por não participar do seguro. Quando os de menor risco desistem de participar, aumenta o risco médio do grupo que continua interessado e, conseqüentemente, o preço final do prêmio. Esta situação se repete indefinidamente para os remanescentes porque os riscos nunca serão iguais para todos.

Como uma maneira de contornar este processo, as companhias criam os seguros que avaliam o risco de cada indivíduo com base na história pessoal e familiar. 0 resultado mais perverso é o aumento do valor do prêmio para os grupos de maior risco (crônicos, idosos), que, provavelmente, não terão condições de pagar e ficarão de fora do seguro. 
Então, a seleção adversa deixa de fora dois grupos: aqueles de menor risco que iniciaram o processo, mas saíram fora do esquema, e aqueles de maior risco que não puderam pagar pelo seguro calculado com base no risco individual.

Conforme a teoria de mercado tradicional, existe falha de mercado apenas no primeiro caso, em que o conhecimento do risco não é igual para consumidor e produtor. No segundo caso, não ocorre uma falha de mercado: apenas os consumidores não têm renda para entrar no mercado. Esta situação nos parece perversa apenas pelo fato de estarmos tratando da saúde, que é um dos direitos fundamentais do cidadão, e parece-nos estranho excluir do acesso aos cuidados de saúde parcela da população que apresenta maior necessidade de atenção, apenas porque não dispõe de recursos.

\section{b) "Risco moral"}

O "risco moral" ocorre quando em determinadas situações, a condição de perfeita competição - racionalidade - não acontece e, então, deparamo-nos com o que é chamado de "risco moral".

o "risco moral" pode ocorrer em sistemas de saúde baseados em seguro privado ou público e também naqueles sistemas que cobrem totalmente os gastos com cuidados de saúde. Nestes casos, existiria uma tendência a ocorrer excesso de demanda, pois o consumidor e o produtor mudam a sua atitude em relação à necessidade de cuidados de saúde, já que as despesas estão completamente cobertas.

Vejamos então: por ter os gastos com cuidados de saúde plenamente cobertos, seja pelo seguro (privado ou público), seja pelo sistema público de saúde, o consumidor considera o fato de ficar doente menos indesejável e tem menos cuidados para permanecer saudável, aumentando os riscos de adoecer. Além disso, como o seu gasto com os cuidados de saúde não se altera em relação ao volume consumido, tenderia a consumir mais do que o necessário. 
Em contrapartida, do lado do produtor, ocorre o excesso de demanda por duas razões. $\mathrm{O}$ u porque ele não tem conhecimento dos custos, ou porque o sistema de saúde público - ou o seguro-saúde (público e privado) - utiliza o mecanismo de pagamento por procedimento², e o médico teria interesse financeiro em prover cuidados de saúde em excesso ou executar procedimentos desnecessários.

Este processo desrespeita um dos principais pressupostos da teoria, a independência entre a oferta e a demanda. É conhecido como a oferta induzindo a demanda porque o médico atua nas duas posições: do lado da oferta - prestando serviço - e do lado da demanda - enquanto agente do paciente que, por não possuir as informações necessárias para a tomada de decisões, consumirá os serviços de acordo com o aconselhado pelo médico.

Além disso, o efeito de a oferta induzir a demanda é reforçado pela existência de uma terceira parte envolvida - o Estado, a empresa ou a companhia de seguros - que vai pagar pelas despesas, o que também não motiva tanto o paciente quanto o médico a moderar o consumo. Temos, como conseqüência deste processo, o aumento dos gastos dos sistemas de saúde públicos e dos custos dos prêmios dos seguros para os consumidores finais.

\section{c) Externalidades}

São os efeitos colaterais da produção ou consumo de um bem auferido por um terceiro. Neste caso, somente é possível calcular os custos e benefícios do consumidor direto. Num mercado não regulado, a existência de externalidades leva a sociedade a produzir bens e serviços num ponto que não é o de equilíbrio de mercado

Sendo assim, se a produção de um bem ou serviço tiver externalidades negativas, e o produtor não tiver que pagar pelos custos destas, ele produzirá muito. Mas, se tiver que adicionar aos seus custos de produção os

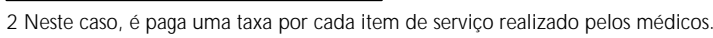


custos das externalidades negativas, o preço do bem ou serviço vai aumentar, diminuindo a demanda, e conseqüentemente a produção, num segundo momento.

No caso da saúde, existe a produção de externalidades positivas, especialmente as de um tipo especial chamado de "bem público"3, cuja principal característica é a inexistência de rivalidade e de exclusão no consumo, ou seja, todos podem consumir o mesmo bem ao mesmo tempo. Para Donaldson \& Gerard (1993) elas podem ser classificadas como:

1 - egoístas, quando o consumo de um bem ou serviço por um indivíduo afeta diretamente o risco para a saúde de outro indivíduo. É o caso das vacinas.

2 - social ${ }^{4}$, ocorre quando o indivíduo fica sabendo que alguém que precisa está recebendo cuidados de saúde necessários, mesmo que isto não afete o seu próprio estado de saúde.

Num mercado não regulado, não é possível contabilizar o desejo do indivíduo de pagar por um benefício externo positivo; assim, o mercado produzirá menos deste bem ou serviço do que seria demandado pela sociedade.

A idéia básica do modelo de externalidade positiva é de que a sociedade compõe-se de indivíduos ricos e pobres e de que os ricos estão dispostos a transferir parte de sua renda para os pobres. É, no entanto, um problema deixar esta transferência de renda ser feita pelo mercado, pois haveria uma tendência de transferir menos do que se isto fosse realizado de outras formas. Além disso, seria muito caro em termos de tempo e esforço. É muito mais eficiente fazer isto através de taxação progressiva ou algum mecanismo de seguro de saúde público.

Alguns podem dizer que seria suficiente subsidiar aqueles que precisam, e deixar os outros cidadãos para o mercado; no entanto, é difícil

3 Segundo Pereira, é mais adequado classificar os serviços de saúde como um bem de mérito, bem de consumo individual cuja utilização dá origem a benefícios superiores àqueles gozados pelo consumidor (...). A qualidade do bem de mérito provém da existência de externalidades positivas tais como os efeitos indiretos da vacinação ou a satisfação que a comunidade obtém ao saber que todos os cidadãos têm acesso aos serviços de saúde em caso de necessidade (1992, p.4).

4 O s autores usam a palavra "caring", que significa cuidado, carinho, preocupação com o outro, no entanto, achamos que social traduziria melhor a intenção dos autores. 
definir quem precisa e prever quanto custará. E, além do mais, quando o governo subsidia o lado da demanda (aqueles que precisam!) não pode ignorar a importância dos médicos do lado da oferta, influenciando o consumo (oferta induzindo a demanda) como já foi visto anteriormente.

\section{d) Distribuição desigual da informação entre produtores e consumidores - a relação de agente}

Não é possível comprar no mercado a melhoria no estado de saúde, a cura. 0 consumidor é obrigado a comprar cuidados de saúde que resultarão em melhoria do estado de saúde, em cura da doença. Existe uma relação técnica entre cuidados de saúde e melhoria no estado de saúde, que é o conhecimento que o médico (produtor) possui e que o paciente (consumidor) não possui.

Sendo assim, existe uma diferença do grau de informação que o consumidor e o produtor detêm. Neste caso, o mercado falha em informar plenamente o consumidor sobre a relação entre determinada ação e o seu futuro estado de saúde; ele precisa do médico que o aconselha a fazer uma determinada escolha e, neste momento, estabelece-se uma relação de agente. Devido a esta posição especial no mercado, os médicos poderão exagerar na quantidade de cuidados de saúde elevando os gastos do sistema ou prover cuidados inadequados e ineficientes se houver conseqüências para 0 sistema de remuneração.

A falta de informação, por parte dos consumidores, sobre o resultado de determinada ação na sua futura condição de saúde coloca os médicos numa posição de agentes, de conselheiros, que atuam em nome dos consumidores. É uma posição bizarra, pois podem influenciar ao mesmo tempo a demanda e a oferta. O s médicos têm o poder de induzir a demanda de seus próprios serviços; assim, os pacientes podem ser induzidos a consumir mais do que necessitariam. 


\section{e) Existência de barreiras}

Podem existir barreiras no mercado do lado da oferta, seja através da regulamentação e controle dos licenciamentos para atuação profissional e do controle do número de vagas nas escolas formadoras, seja por restrições no número de consultas, exames, natureza das patologias assistidas, etc.

Como os consumidores (pacientes) não conhecem plenamente as repercussões em seu estado de saúde pela adoção de determinados cuidados, é possível que, se pudessem escolher livremente no mercado, cometessem graves erros. Sendo assim, o Estado, que tem como uma de suas atribuições zelar pelo bem-estar de seus cidadãos, deve intervir regulando este mercado.

No entanto, esta regulação pode transformar-se na defesa da corporação médica, uma vez que a redução de oferta tende a aumentar os preços. O u seja, se a regulação da entrada de novos profissionais no mercado for feita de tal forma que a oferta de profissionais seja menor que a demanda, haverá uma tendência ao aumento do valor dos salários.

Esta é uma situação contraditória, pois, com o objetivo de proteger os interesses do consumidor, coloca-se a exigência do licenciamento que, por seu turno, dá aos médicos um poder de mercado especial, principalmente quando são eles mesmos quem decide o número de novos médicos no mercado.

Utilizando os conceitos da teoria tradicional da oferta e da demanda, deparamo-nos com inúmeras falhas de mercado no setor da saúde. A existência dessas falhas é uma indicação de que o mercado, neste caso, não consegue promover o equilíbrio entre a oferta e a demanda, e, assim, justifica-se a intervenção do Estado na regulamentação, ou mesmo de forma mais direta, na produção de serviços.

A partir desta teoria, procurando avançar na compreensão das especificidades do setor saúde, alguns autores (M cGuirre, Henderson, Mooney, 1992) introduziram o conceito de necessidade. Segundo eles, a 
demanda por saúde é uma expressão da "necessidade por serviços de saúde", que é um conceito relativo, pois resultante do julgamento da sociedade e do indivíduo sobre a importância dos custos e benefícios de determinado tratamento.

O conceito de necessidade já parte do reconhecimento de que, no setor saúde, a oferta e a demanda não interagem da maneira convencional: a demanda não é autônoma, e a oferta tem um papel importante na determinação dos níveis de consumo.

Como vimos anteriormente, este processo ocorre devido à falta de informações e às incertezas sobre os efeitos do consumo dos serviços de saúde. 0 médico estabelece uma relação de agente com o paciente, indicando o tratamento, já que este não tem condições de julgar a melhor alternativa, seja antes ou depois do consumo. E, quando o produtor atua como agente do consumidor, pode ocorrer um nível de consumo diferente daquele que ocorreria caso o consumidor estivesse completamente informado e pudesse escolher livremente (McGuirre, Henderson, Mooney, 1992).

0 papel desempenhado pelo médico torna difícil a separação entre a oferta e a demanda. Temos, então, que a demanda por serviços de saúde é induzida pela oferta e, portanto, não existem as condições para a perfeita competição. A existência de falhas torna o mercado ineficiente na provisão de bens e serviços

Ademais é importante refletirmos, ante esta onda de liberalização da economia, quais as áreas que devem receber um tratamento diferenciado, seja por suas características intrínsecas (existência de falhas de mercado), seja pela importância social que têm. Não é possível, em alguns casos, apenas buscar o equilíbrio no mercado ou nas contas públicas

É muito pouco provável que se alcance a eqüidade através das leis do mercado porque este reforçará o padrão existente de distribuição, que é normalmente definido pelo nascimento, pela renda e pela educação. Além disso, tenderá a alocar os serviços conforme a capacidade de pagamento, prejudicando especialmente os mais desfavorecidos e doentes. 
É preciso que a sociedade decida como vai garantir os direitos estabelecidos para os seus cidadãos. A saúde é um dos direitos básicos que permite ao cidadão viver, trabalhar e produzir. Não podemos tratar a saúde como uma mercadoria qualquer: a prestação de serviço de saúde é diferente da produção, por exemplo, de salsichas ou de automóveis. Depois desta análise, sentimo-nos suficientemente amparados para, mesmo dentro dos marcos conceituais da teoria do mercado, justificar a intervenção do Estado no setor saúde como a única forma de otimizar a alocação dos escassos recursos disponíveis na sociedade.

\section{Referências bibliográficas}

BARREN . Economics of the welfare state. London: W eindenfield \& N icolson, 1987.

BENNET, S. \& MILLS, A. The public/private mix in health systems and the role of ministries of health. Paper prepared for a WHO Interregional M eeting M éxico: 1991.

BEN NET, S. The mystique of markets: public and private health care in developing countries. PHP , 4, 1991.

BIRSD ALL, N. Tougths on good health and good goverment. D eadalus, 118, 1989.

CALM BACH, G. V. Microeconomia. Rio de Janeiro: Fórum Editora, 1969.

DO NALDSO N, C. \& GERARD, K. Economics of health care financing: the visible hand. London: M cM illan Press, 1993.

LE GRAND, J. \& ROBINSO N, R. The economics of social problems. M acM illan, 1976.

MAN SFIELD, E. Microeconomia. Rio de Janeiro: Campus, 1978.

MCGUIRE, A.; HENDERSON, J.B. \& MOONEY, G. The economics of health: an introdutory text London: Routledge and Kegan Paul, 1992.

NO RM AND, C. Economics, health and the economics of health. British Medical Journal, 303, dec 1991, p.21-23. 
Sociologias, Porto Alegre, ano 4, № 7, jan/jun 2002, p. 122-135

PEREIRA, J. G lossário de economia da saúde, texto preparado para o II W orkshop Internacional de Economia da Saúde, São Paulo, Junho 1992, mimeo.

ROBERTS, J.A. Marketeers and the NHS. In: Ian Taylor. The social effects of free market policies. Harvest-Wheatsheaf, 1990.

SIM O NSEN, M.H. Teoria microeconômica, vol. 3. São Paulo: Fundação Getúlio Vargas, 1969. 


\section{Resumo}

As atribuições do Estado com relação à garantia dos direitos de acesso aos cuidados de saúde ampliaram-se após a promulgação da Constituição Federal de 1988 que introduziu a garantia do acesso universal e integral. Além disso, a efetiva política de descentralização das ações de saúde para estados e, principalmente, para os municípios gerou a necessidade de debater sobre responsabilidades e atribuições dos diferentes níveis de governo, dos cidadãos, do Estado e dos setores público e privado. E por fim, as políticas públicas voltadas à redução da intervenção do Estado na economia também trazem à tona essa questão polêmica. N esta medida, propusemo-nos a discutir neste artigo as falhas de mercado que ocorrem no setor saúde e justificam a intervenção do Estado para alcançar a otimização na alocação e na distribuição dos recursos.

Palavras-chave: economia da saúde, saúde pública, demanda em saúde, regulação em saúde. 